\title{
ASSESSMENT OF THE DIAGNOSTIC SUITABILITY OF NET THERMAL EFFICIENCY OF MARINE DIESEL ENGINE
}

\author{
Rafał Pawletko, Stanisław Polanowski, Kazimierz Witkowski \\ Gdynia Maritime University \\ Faculty of Marine Engineering \\ Morska Street 83, 81-225 Gdynia, Poland \\ e-mail:stpolanowski@gmail.com,pawletko@am.gdynia.pl \\ wika@am.gdynia.pl
}

\begin{abstract}
This article applies to searching for symptoms and diagnostic parameters pointing in a deterioration in the quality of the combustion process in marine diesel engines. It was assumed that diagnostic parameters should give clear information regardless of engine load or with respect to the mean indicated pressure. The proposed cycle and sectional net thermal (heat) efficiency characteristics and also dimensionless net heat release rate were analysed. In order to obtain the state of deterioration of the injection process simulation of discalibration (larger diameter) of injector holes was performed. The simulation was carried out by the enlarged of diameter of the injector holes form $0.375 \mathrm{~mm}$ to $0.385 \mathrm{~mm}$. Deterioration of the formation and growth of fuel spray droplet diameter is result of such simulation. The study was conducted on a laboratory engine Sulzer Al25/30. The study was carried out according to active experiment plan, during which the selected engine failure of the injection system was simulated. Measurements of pressure of combustion were performed by means of tensometric sensors of Spice Company on the indicator valve. The analysis found that in the event of injector nozzle faults (discalibrated holes) significantly decreases the net thermal efficiency $\eta_{c}$ cycle, and there are significant oscillations of net heat release rate $\eta_{q}$. The research was preliminary and is expected to further studies to confirm the obtained results.
\end{abstract}

Keywords: indicator diagram, thermal efficiency, diesel engine diagnosis

\section{Introduction}

Diagnosis of the fuel injection system is a difficult and complex issue especially in terms of fault localization. The problem is particularly important for marine engines, in which there are high pressures and temperatures at the end of the compression and combustion process. As a result, the working process is less sensitive to the quality of fuel atomization, which is affected by such failures as discalibrated (fuel) injection nozzles, clogged (blockage) fuel injection nozzles, improper tension of fuel injector springs. In existing diagnostic systems which are relies on cylinder pressure measurements, the diagnostic inference is based on the analysis of the maximum pressure and mean indicated pressure with respect to the values for neighbouring cylinders or medium for all engine. These diagnostic parameters are accumulation type and there are not capable for identify the type of fault.

Another important issue is to ensure during the testing so. Diagnostic load - loads of the same value at each diagnosis. At the operating conditions is virtually impossible. This approach to diagnosis makes lots of difficulties even in the laboratory stands.

In view of the above limitation, direct analysis of the indicator diagram is difficult, therefore, other values (parameters) derived on the basis of information contained in the indicator graphs are sought, such as the first order derivatives of pressure traces.

Another important option to increase the amount of information obtained from the indicator diagram is the net heat release characteristics determination. The use of diagnostic for net heat release characteristics $Q_{n}$ is justified by lack of information about cooling heat loss $Q_{c o}$, exhaust and crevice loss $Q_{o u}$.

Rate of net heat release $\mathrm{d} Q_{n}$ can be written as follows $[1,4]$ : 


$$
\mathrm{d} Q_{n}=\mathrm{d} Q_{c b}-\mathrm{d} Q_{c o}-\mathrm{d} Q_{o u},
$$

where $\mathrm{d} Q_{c b}$ is a heat released by fuel combustion.

From the measurement reasons and for diagnostic purposes it is convenient to consider the pressure traces in the area of the crank angle $\alpha$. For an ideal gas, dividing equation (1) by the cylinder volume of a cylinder $V_{S}$, rate of released heat (angle) $q$ is calculated from the formula:

$$
q=\frac{1}{V_{S}} \frac{\mathrm{d} Q_{n}}{\mathrm{~d} \alpha}=u+l_{i}=(\kappa-1)^{-1} v \frac{\mathrm{d} p}{\mathrm{~d} \alpha}+\kappa(\kappa-1)^{-1} p \frac{\mathrm{d} v}{\mathrm{~d} \alpha},
$$

where:

$u$-increase in the internal energy per angle of rotation,

$l_{i}$ - increase in internal work,

$\kappa$ - isentropic exponent,

$v$ - dimensionless volume of the cylinder, $v=1-s_{\alpha}+(\varepsilon-1)^{-1}$,

$s_{\alpha}-$ dimensionless piston way calculated from the DMP,

$\varepsilon$ - compression ratio.

After the introduction of these modifications the main unit of heat release rate $q$ in the SI system would $\left[\mathrm{J} / \mathrm{m}^{3} \cdot 1^{\circ} \equiv \mathrm{Pa} / 1^{\circ}\right]$. For practical reasons, since the cylinder pressure is still measured and expressed in bars, $q$ is taken for the unit [bar $/ 1^{\circ}$ ] or [bar/deg CA].

The total (cumulated) generated heat $\mathrm{Q}$ in range from the beginning of compression $\alpha_{c}$ to the $\alpha$ angle is expressed by the formula:

$$
Q=U+L=\int_{\alpha_{c}}^{\alpha} u \mathrm{~d} \alpha+\int_{\alpha_{c}}^{\alpha} l \mathrm{~d} \alpha,
$$

where: $\mathrm{U}$ and $\mathrm{L}$ are the internal energy and the indicated work done in range of angle $I\left[\alpha_{c}, \alpha\right]$, respectively. According to the adopted unit for $q$, a unit of $Q$ is [bar].

The direct benefit of the diagnostic analysis of the heat release characteristics is that in a specified period of rising, angle of inclination of $q$ and $Q$ characteristics is independent on the engine load (Fig. 1).
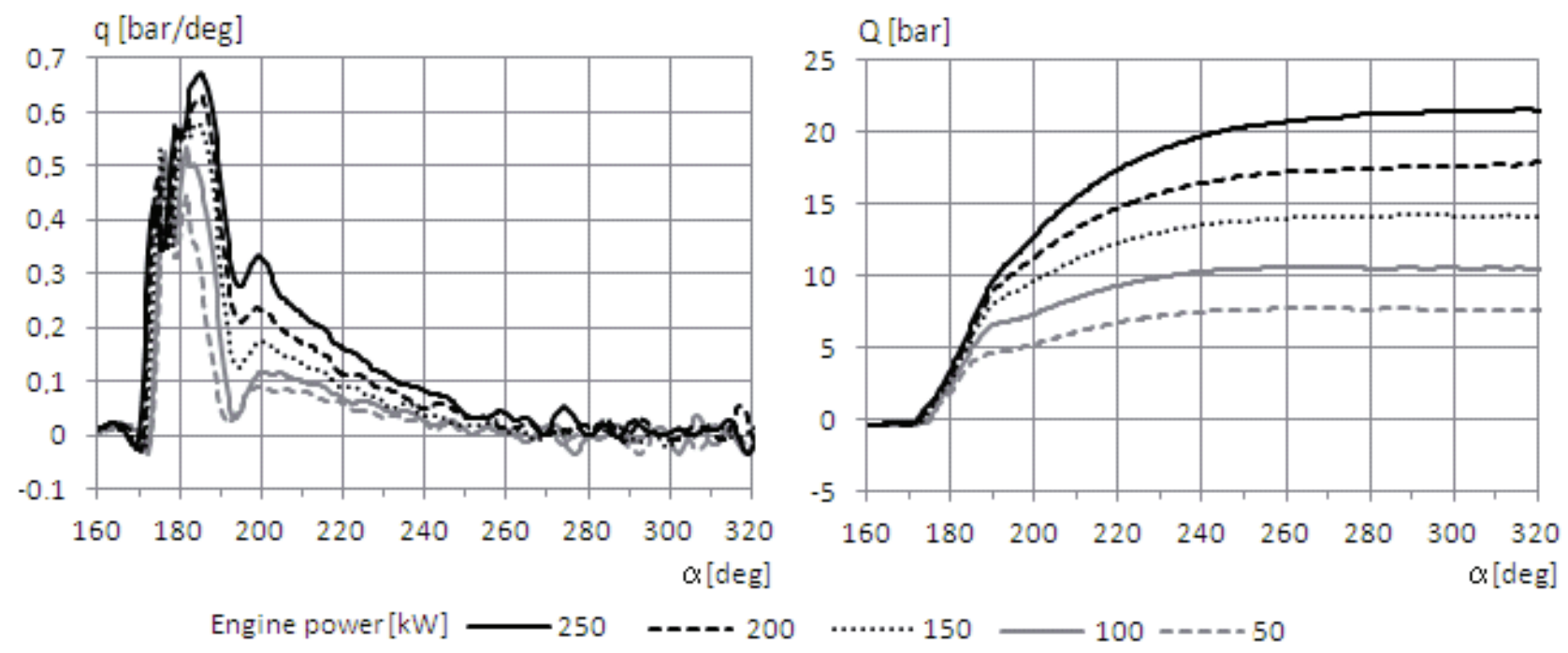

Fig. 1. The net heat release rate $q$ and total generated heat $Q$ characteristics for different engine load for the laboratory engine (Al 25/30) and the nominal (reference) state

In this case (Fig. 1) the steepness of the characteristics of a fixed interval is approximately $172-177^{\circ} \mathrm{CA}$. It is expected that the steepness of the curves in this range will decrease with the loss of tightness of the fuel injection system. 
In the case of such failures as clogged (loss of patency) fuel injection holes, discalibrated fuel injection holes, improper tension spring of injector we have difficulty in recognizing these failures and interpretation of diagnostic test results.

The article examined the possibility of using for this purpose the following efficiency characteristics (indicators): point net thermal efficiency, interval net thermal efficiency and net thermal efficiency of the cycle.

For experimental results processing, the same method of smoothing of indicator diagrams using multiple polynomial (Savitzki - Golay filter) and TDC thermodynamic were used $[2,3]$.

\section{Assessment of the relevance of the diagnostic use of the net interval thermal efficiency}

The net interval thermal efficiency can be defined as follows:

$$
\eta_{I}=\frac{L_{i u}}{Q}
$$

where $L_{i u}$ is the indicated useful work (after subtraction of the compression work).

Figure 2 compares the traces of efficiency for simulated fault (discalibrated fuel injection nozzles) to nominal (reference) state for different engine loads.
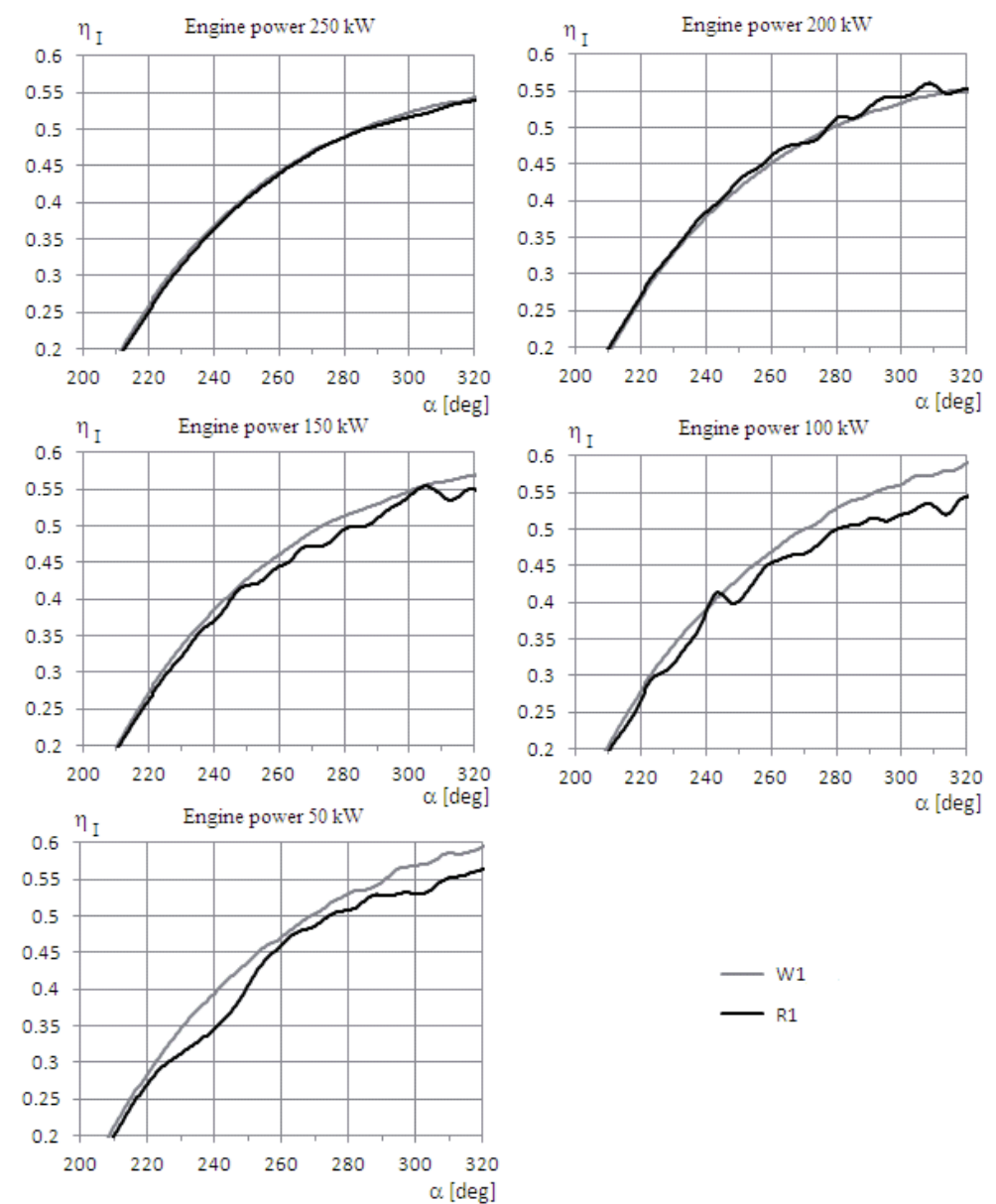

Fig. 2. Comparison of the net interval thermal efficiency for various diagnostic simulation of various engine load test: W1-nominal state, R1-simulated fault

As shown in Fig. 2, in the case of simulation - recalibration of injector nozzles R1 deviations are larger and oscillate. These signals (symptoms) are not strong, and their confirmation is necessary to repeat and extend the test. 
Net thermal efficiency of the cycle is defined as follows:

$$
\eta_{C}=\frac{p_{i}}{Q_{\max }}
$$

where:

$p_{i} \quad$ - cycle mean indicated pressure,

$Q_{\max }$ - maximum of total net generated heat for work cycle.

Figure 3 shows the traces of cycle efficiency as a function of mean indicated pressure.

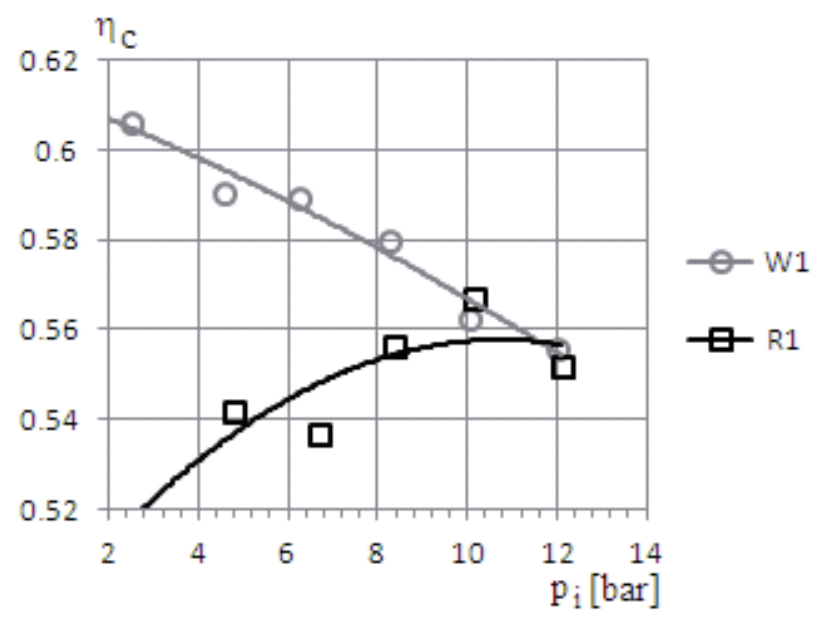

Fig. 3. Traces of net thermal efficiency (total) net as a function of mean indicated pressure for the nominal state (W1) and simulated fault (R1)

As shown in Fig. 3 for simulation R1, a significant decrease in the efficiency at lower loads. Starting from $200 \mathrm{~kW}$ efficiency reached values typical of the standard. This symptom has its physical justification, with the diameter of the injection holes increase fuel atomization is deteriorating [1]. With the engine load increase effect is decreasing as a result of rising temperatures and pressure in the cylinder.

\section{Assessment of the relevance of the diagnostic use of the point indicator of net thermal efficiency}

The point index of net thermal efficiency is defined as follows:

$$
\eta_{P}=\frac{l_{i u} \Delta \alpha}{Q},
$$

where $l_{i u}$ is an increase of useful indicated work attributable to elementary angle rotation of the shaft.

Curves of indicator in crank angle domain only slightly dependent on the engine load (Fig. 4).

As shown in Fig. 4, analysed simulations (damage) did not significantly affect the traces. Whether they are actually symptoms of simulated damage and no sign of the impact of other factors can be explain further research. It seems that it is appropriate to consider the indicator in which the size of the reference will be no heat generated $Q$ but the internal energy $U$.

\section{Assessment of the relevance of the diagnostic use of the point indicator of released heat}

The point indicator of released heat is defined as follows:

$$
\eta_{q}=\frac{q \Delta \alpha}{Q} .
$$


The purpose of this indicator was to become independent the trace of heat release of the engine load in the range of fuel combustion, which proved to be an effective treatment when compared sequences of heat release $Q$ for the nominal state shown in Fig. 1 with the traces shown in Fig. 5.
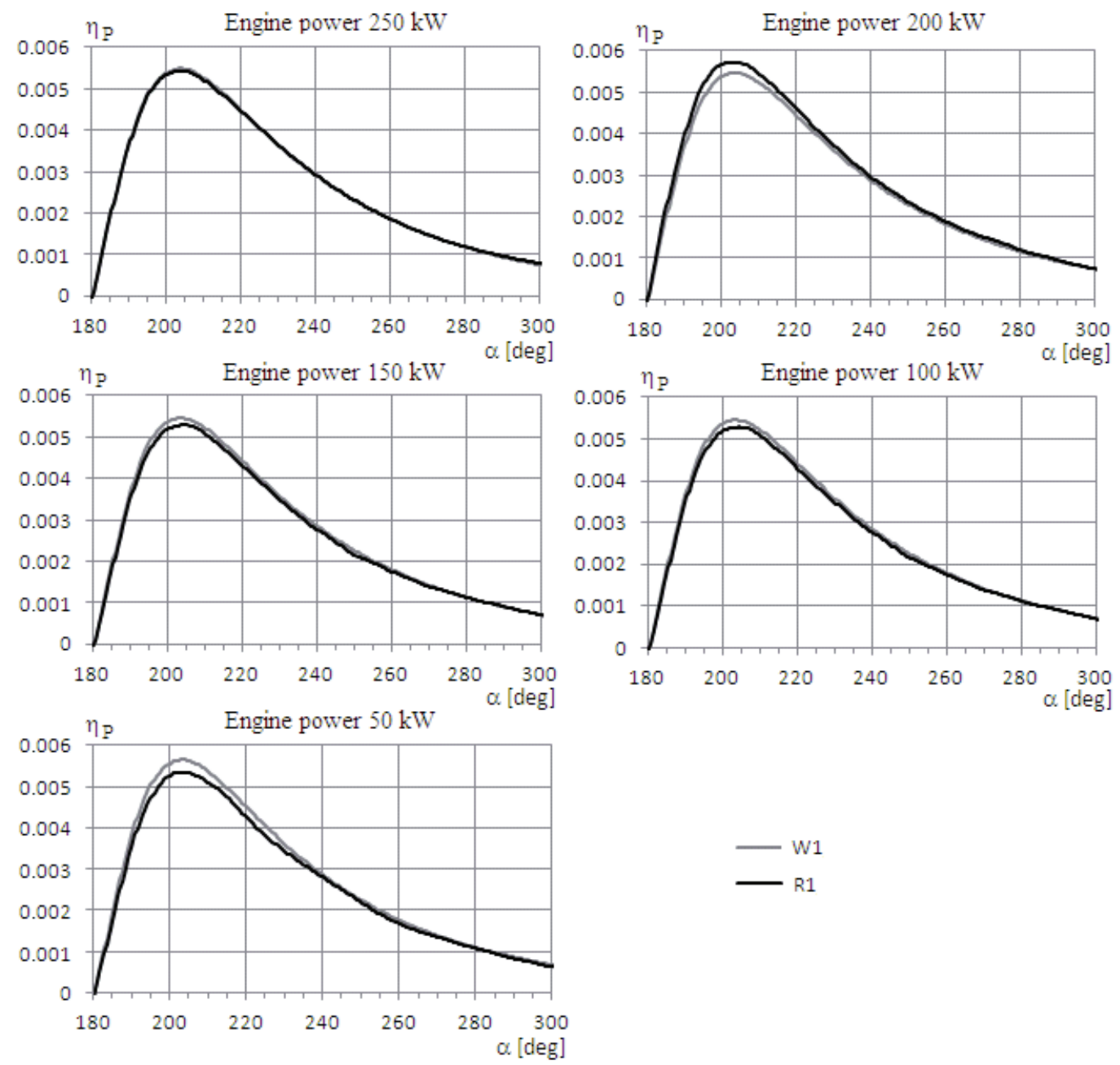

Fig. 4. Comparison of the point indicator of net thermal efficiency for a variety diagnostic simulations and various engine load: W1-nominal state, R1-simulated fault

Comparison of the curves in Fig. 5 reveals the appearance of the signal (oscillation) for the simulation of recalibration injection holes R1 to the smaller loads, ranging from $200 \mathrm{~kW}$. An explanation of whether the cause of this phenomenon is investigated damage requires further study and replicate experiments.

\section{Conclusions}

Due to the variability in engine load during operating conditions, the direct use of the heat release characteristic is difficult because of the need to have a reference heat release traces.

The results of the tests and analyses indicate that the diagnostic accuracy of the injection process can be carried out by means of a cycles and sectional net thermal efficiency, as well as dimensionless point net heat release rate.

In the case of net cycle thermal efficiency $\eta_{C}$ there was a significant decrease in its value for the engine power of $150 \mathrm{~kW}$ and smaller loads. In the case of the dimensionless net point heat release ratio $\eta_{q}$ significant increase in the oscillation was found for lower engine loads, starting from $200 \mathrm{~kW}$ power output in the range of combustion of fuel. 
It was also found some deviations of net point thermal efficiency $\eta_{P}$ in the range of occurrence of the local maximum but observed deviations are difficult to interpret.

Experimental studies were preliminary and require repeats and for higher engine loads.
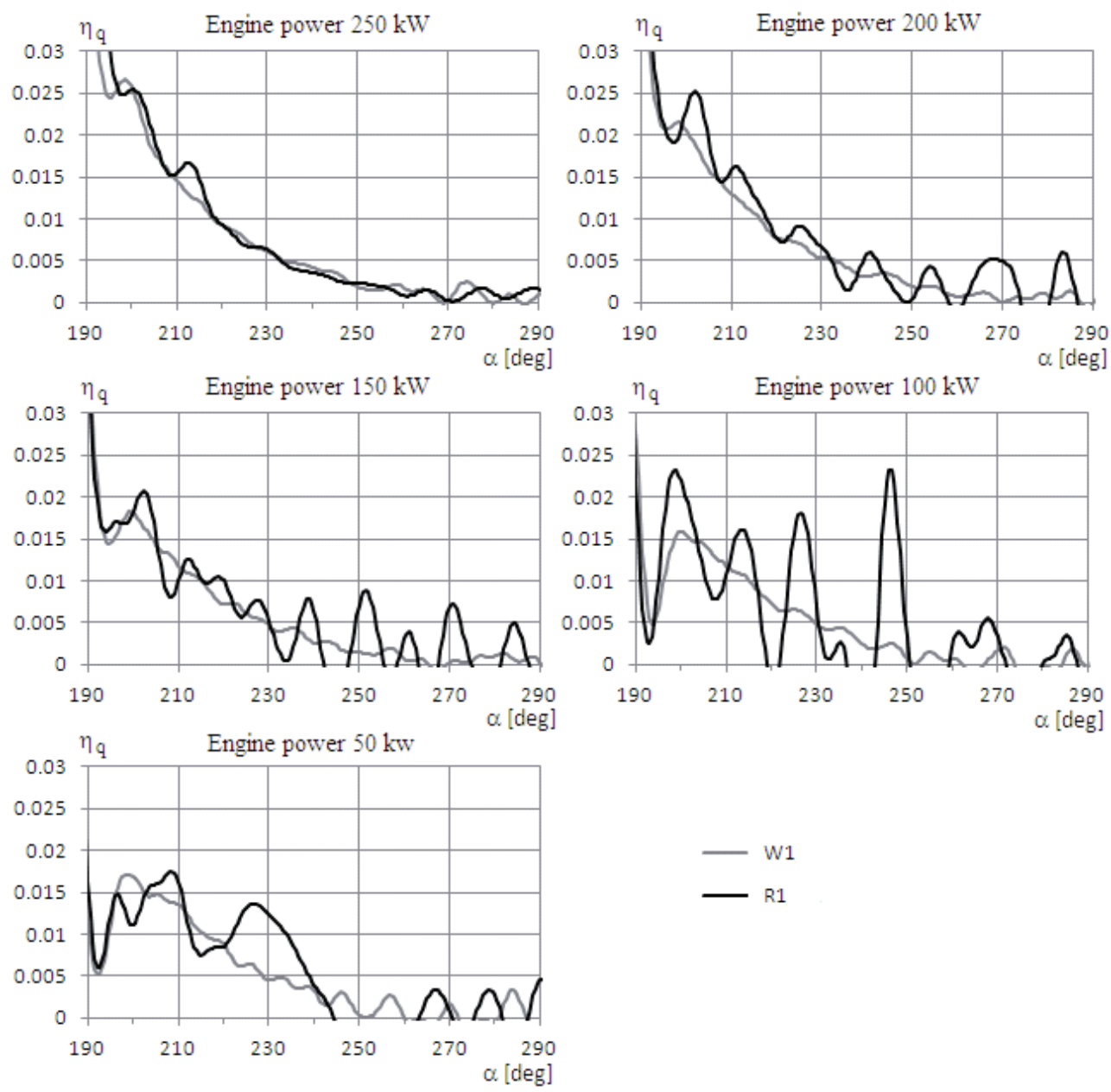

Fig. 5. Comparison of the point indicator of released heat for a variety diagnostic simulations and various engine load: W1 - nominal state, R1 - simulated fault

\section{References}

[1] Heywood, J. B., Internal Combustion Engine Fundamentals, McGraw-Hill, 1988.

[2] Pawletko, R., Polanowski, S., Research of the Influence of Marine Diesel Engine Sulzer AL 25/30 Load on the TDC Position on the Indication Graph, Journal of KONES Powertrain and Transport, Vol. 17, No. 3, pp. 361-368, 2010.

[3] Polanowski, S., Determination of Location of Top Dead Centre and Compression Ratio Value on the Basis of ship Engine Indicator Diagram, Polish Maritime Research, No. 2 (56), Vol. 15, Gdynia 2008.

[4] Rychter, T., Teodorczyk, A., Modelowanie matematyczne roboczego cyklu silnika tłokowego, [in Polish], PWN, Warszawa 1990. 